\title{
Environmental Kuznets curves: environmental wealth and spending
}

\author{
B. Cushing-Daniels \& B. A. Kaiser \\ Gettysburg College, PA, USA
}

\begin{abstract}
The existence of an environmental Kuznets curve (EKC) - a pattern of pollution that rises and then falls with higher levels of real gross domestic product per capita - remains controversial. Previous research fails to address simultaneity concerns. We match empirical evidence on EKCs with theoretical underpinnings and investigate the roles of endowments, spending, and technology. Income elasticity of demand for environmental quality may vary with output levels. Varying separability of pollution and production across goods may mask the presence of EKCs. Demand and supply must be contextualized by the resource endowment. We describe a model of the connection between collective environmental provision (government spending) and economic prosperity using data at the US state level. We examine the inverse of the traditional EKC: the relationship between state spending on natural resources and the environment and real gross state product, enabling identification of demand and supply components of the environmental quality-economic growth tradeoff. Our results suggest non-linear income effects for environmental quality and support the hypothesis that at higher incomes, environmental quality is a luxury good. An EKC is best described as a moving frontier of what people have (endowment), what people want (demand), and what is feasible (technology/ supply). In this light, the puzzle of where and when we witness EKCs should be considerably demystified.
\end{abstract}

Keywords: environmental Kuznets curve.

\section{Introduction}

Much of the research on income and environmental quality tests specifically for the existence of an environmental Kuznets curve (EKC) - a pattern of pollution 
that rises and then falls with higher levels of real gross domestic product (RGDP) per capita. (For the original Kuznets curve reference, see Kuznets [5].) The evidence is decidedly mixed (Aldy [1]; Harbaugh et al. [4]; List and Gallet [6]; Yandle et al. [10]). The existence of an inverse-U relationship between incomes and pollution levels seems to depend on the pollutant in question. We suggest that the frequent conflation of demand side and supply side conditions with respect to environmental quality drive this confusion and propose a unifying theoretical framework to clarify the relationship between economic prosperity and environmental quality.

To investigate better the potential tradeoff between natural capital assets (environmental quality) and physical capital assets as income varies, we examine state spending on natural resources and the environment and real disposable income, instead of the more typical empirical work linking pollutants with output. Using this reversal, we can identify better the demand side effects from the supply side effects.

In this paper, we seek to match existing empirical evidence on EKCs with broad theoretical underpinnings and to investigate empirically the relative roles of environmental endowments, environmental spending, and technology. In other words, we seek to understand how the environment fits into growth when considering the conflated questions of what people have in their environment, what people want from their environment and economy, and how feasible it is for them to get it. First, in section 2 we synthesize the existing research into a set of hypotheses about why some measures of pollution appear to have stronger EKC traits than others do. In section 3 we describe an empirical model to investigate the connection between collective choices about direct environmental provision, in the form of government spending on the environment, and economic well-being as measured by gross output. We look at U.S. state level data in order best to control for political and temporal influences on growth. In section 4 we present our findings and in section 5 conclude.

\section{Theoretical structures}

\subsection{Demand-side arguments}

At higher per capita income levels, environmental quality may become a luxury good. More specifically, environmental quality may simply be a normal good, where an increase in income monotonically increases demand for environmental quality. In that case, any inverted-U relationship between pollutants and income must be driven by supply side concerns. However, the EKC is also explained if the environment is an inferior good at low income levels, but becomes a normal good at higher income levels. Fig. 1 illustrates the possibilities.

The environment may be an increasingly inferior good as incomes rise from low levels, and then an increasingly normal good as they rise further. This represents a case where the citizenry chooses to draw down its natural capital in exchange for consumption or investment in physical capital that raises economic output at low levels of income, but collective preferences reverse at higher 
incomes, reflecting the desire for increasingly more environmental goods as incomes rise. This would indicate that the rate of return on natural capital in its pristine state had become higher than the rate of return on natural capital as an input to other forms of production.

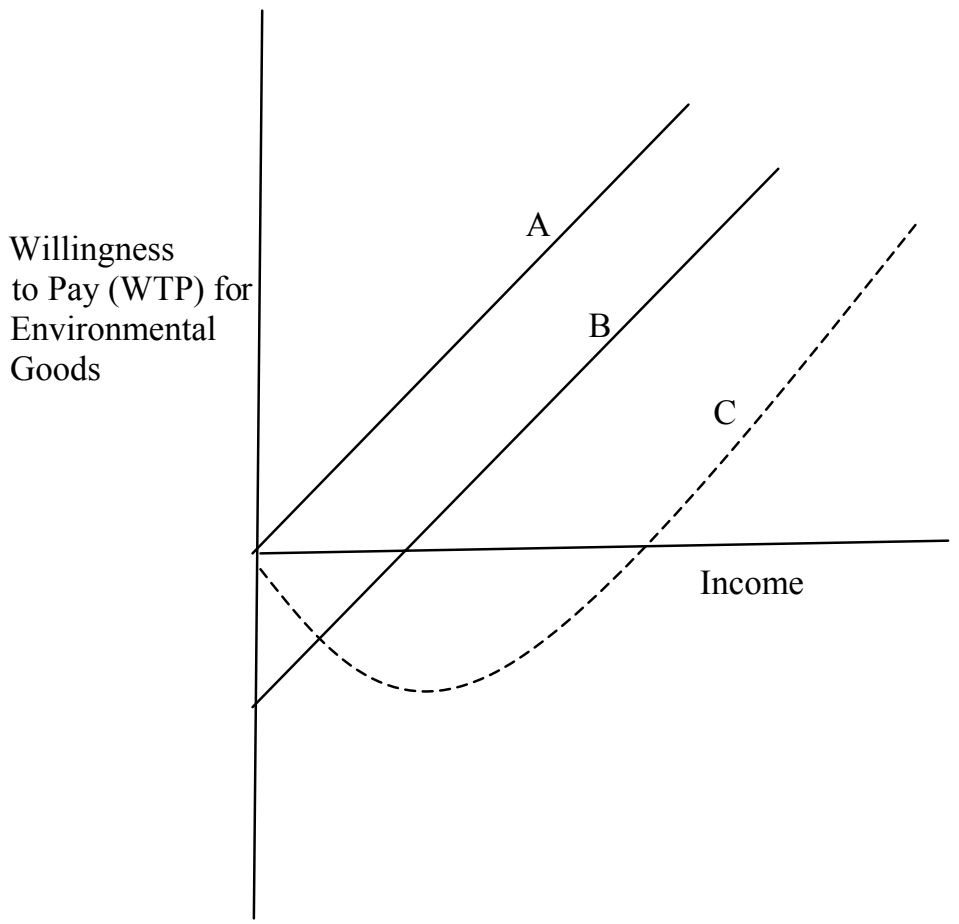

Figure 1: Possible income-WTP paths for environmental goods. If normal, WTP will increase with income (A); if inferior then normal, negative WTP will reflect drawdown of resources (B). If goods are increasingly inferior at low levels of income (C), WTP alone generates EKC conditions.

It may also reflect changes in the income-effect's wedge between Willingness-to-pay for environmental quality (WTP) and Willingness-to-accept environmental damages (WTA), with the wedge shrinking as a reduced resource base erodes existing environmental wealth. See also Roca [7].

\subsection{Supply-side arguments}

Production externalities create environmental degradation at levels that are dependent on both market production levels and technology used. If production increases, then associated pollution can be expected to increase unless the input mixture or the technology changes. Technology may be able to separate production from pollution, as for example with leaded gasoline. Alternatively, 
substitutions in input mixes may also reduce pollution as output increases; e.g. exchanging lesser polluting natural gas for other more polluting carbon-based fuels. If production and pollution are separable, through either technology or input substitution, environmental quality can be supplied independently as income increases. Without this capability, increases in income will increase the output of pollution, reducing environmental quality monotonically. Fig. 2 illustrates the potential supply paths for environmental quality (measured as pollution reduction) under different technological assumptions.

Environmental
Quality:
(Pollution
Reduction)

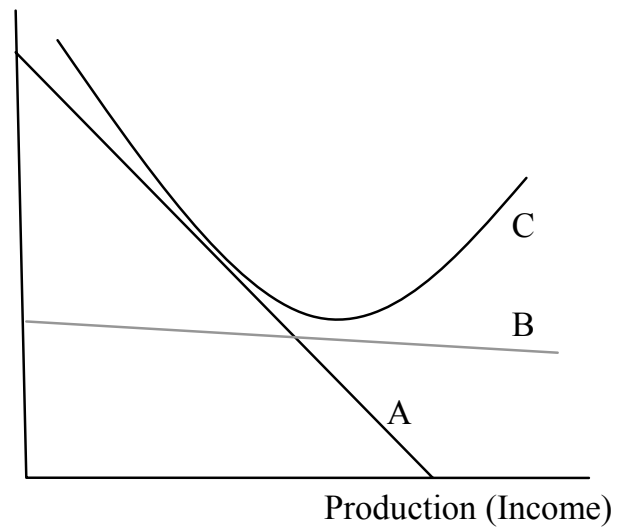

Figure 2: Possible income-production paths for the environment. Quality may deteriorate monotonically from production (A), or be mostly unrelated (B); if production is separable from pollution (C), supply side effects generate the EKC.

\subsection{Resource endowments}

The initial resource endowment will affect supply and demand. Thus to accurately compare how income and environmental quality vary with respect to one another, one must account for differences in the resource endowment and its use. For example, the western United States and the eastern United States not only have different mineral resource endowments, but have used these endowments differently over time.

\subsection{A unified theory for EKCs}

Pollutants will differ in both demand and supply concerns. The wide range (approx. $\$ 10,000$ to $\$ 57,0002003 \$$ US) of estimates for turning points in EKCs for different pollutants provide quantitative evidence for these differences. (See Cole et al. [3], in which they compile evidence that different pollutants vary in EKC turning point estimates from a low of $\mathrm{SO}_{2}(\sim 10,0002003 \$ \mathrm{US})$ to a high of $\mathrm{CO}_{2}$ ( 40,000-57,000 2003\$US).) Attempts to understand this range have fueled 
the debate over whether there actually is such a thing as an Environmental Kuznets Curve. Our interpretation of the situation is that the variation across pollutants stems from differences in demand and supply functions for specific characteristics of the pollutants. See also Shafik [8].

We hypothesize, then, that any potential EKC is a factor of demand, supply, and resource endowments. Figs. 1 and 2 together show that the potential outcomes for environmental quality and income may vary widely as demands for environmental quality and supply capabilities are balanced and evolve with changing incomes and originate with differing endowments. We seek to investigate this unified theory by focusing first on the question of demand and then on the question of resource endowments. EKCs will occur when combinations of demand, supply, and resource endowments align to reflect an inverse-U relationship between income and pollution, or a U-shaped relationship between income and environmental quality.

\section{Model and estimation}

\subsection{Overview}

We examine active political intervention to improve environmental quality as a function of natural resource endowment and income levels to understand more clearly the demand side of the EKC. Changes in state-level spending on environmental quality reflect changes in demand for environmental quality and other publicly provided goods and services as constraints on budgets change with income and changes in tastes and preferences (Clingermayer and Wood [2]). Furthermore, capital deepening arguably stems from intensive resource use, as a necessary corollary to any resource base (Wright [9]). Thus, less developed communities have an incentive to utilize the resource base to produce physical capital and wealth, which later might be converted back to environmental quality. We therefore exploit both political and economic choices to identify demand and supply effects to the extent possible.

\subsection{Data and methodology}

The data for this study come from a number of government publications, including various editions of the Statistical Abstract of the United States, Government Finances, State Government Finances, and Public Employment. All expenditure figures are denominated in 1982 dollars. (Many thanks to Gary Painter, Associate Professor, School of Policy, Planning and Development, University of Southern California, for providing many of the political variables used herein.)

From 1972 to 2002, overall natural resource spending has increased from $\$ 62,448$ to $\$ 440,004$ per state. This growth has been neither uniform nor consistent, however. For example, in the decade of 1983-1992, some states reduced their spending on natural resources by as much as half, and other states increased theirs by up to $170 \%$. Four of the states that reduced spending (MS, 
CA, LA, DE) had spending levels above the national average in 1983, while IN was already below the national average and $\mathrm{OK}$ was close to it. Furthermore, the average state ratio of natural resource spending to disposable income per capita exhibits a U-shape over this period, beginning at $15.3 \%$ in 1972 , dipping to $11.9 \%$ in 1978 and 1979 , and then increasing to $16.5 \%$ in 2002 . Clearly, any story explaining the relationship between income and environment will need more than one dimension.

We have insufficient information to separately identify demand and supply equations for environmental quality. Instead, we focus on natural resource expenditures, defined as state spending on the environment and natural resources, as the reduced form outcome of the natural resource endowment and the demand for environmental quality. Per capita income, the size of the state bureaucracy, unemployment, and population are expected to reflect mainly demand-side concerns, while per capita debt levels, exports of agricultural goods, and the intensity of mining resource use are expected to reflect primarily supply-side concerns. Since income's effects may be non-linear, a quadratic term is included for per capita disposable income. Population is in 1000s. Dollar figures are all in thousands of 1982 dollars. The bureaucrat variable is a count (1000s) of state and local government employees.

Per capita debt is long-term real debt and is interpreted to reflect opportunity costs of capital development or resource exploitation. Fruit and wheat exports are in millions of dollars. They are included separately because fruit production may rely more on overall environmental quality than grain production and because they reflect differing endowment characteristics. Mining intensity, reflecting the availability and use of natural resources, is the ratio of past producing mines to total known exploitable mines for the state. This figure does not vary by year but reflects the conditions in the year 2000 .

As there is likely to be significant heterogeneity across states, we apply both random-effects and fixed-effects models to the panel data to test for the robustness of results across specifications. Both models correct for first-order autocorrelation. As the data contain observations for all 50 states over the sample period, the fixed effects specification is more appropriate, but we include the random effects models both as a robustness check and for comparison to previous work on EKCs in cross-country settings. The random effects model, which can accommodate the time-invariant mining intensity variable, provides additional insight into the role of the resource endowment and its use. The fixedeffects specification assumes that the differences between states' environmental spending can be viewed as parametric shifts of the regression function, and the effect of mining intensity cannot be separated from other state level differences.

\section{Results}

Table 1 displays the results of the two empirical models. The fixed effects model allows the states to have differing base levels of spending independent of other concerns. These fixed effects may reflect either demand or supply impacts. The random effects model assumes instead that the state level differences are 
randomly distributed around the same mean, but allows incorporation of the level of mining intensity into the model. This variable's significant negative impact on the random effects model suggests that the state fixed effects do reflect differences in state resource endowments and the intensity with which they have been used over time. The use of the fixed effects model to identify the supply component of the environmental quality-economic growth tradeoff is an improvement over existing models.

Natural resource expenditures appear non-linearly related to income. The random effects model illustrates environmental spending as becoming increasingly desirable as income increases. This supports the hypothesis that environmental quality is a luxury good.

The fixed effects model directly supports the existence of an environmental Kuznets curve as the linear and quadratic terms act in opposite directions, with increases in income decreasing environmental spending at low incomes and increasing it at higher levels of income. The fixed effects model may be more appropriate because it allows resource endowments and intensity of use to vary across states (or nations), we find support for the environmental Kuznets curve's general existence as we incorporate resource endowments into the analysis. The turning point here is found to be just over $\$ 29,000$ - higher than most countries' per capita income.

Table 1: Determinants of natural resource expenditures (standard errors in parentheses).

\begin{tabular}{|l|c|c|}
\hline \multicolumn{1}{|c|}{ Variable } & Fixed Effects Model & Random Effects Model \\
\hline Population & $99.9^{* * *}$ & $33.4^{* * *}$ \\
& $(7.5)$ & $(3.7)$ \\
\hline Per Capita Disposable & $-13.3^{* * *}$ & $\left(3.0^{* *}\right.$ \\
Income & $(4.9)$ & $0.0002^{*}$ \\
\hline Per Capita Income Squared & $0.0005^{* * *}$ & $(0.00009)$ \\
\hline Unemployment & $(0.0001)$ & -1481.9 \\
& $-2286.8^{* *}$ & $(1235.2)$ \\
\hline Bureaucrats & $(1136.7)$ & 69.9 \\
& $159.1^{* * *}$ & $(49.8)$ \\
\hline Per Capita Debt & $(45.9)$ & -2.9 \\
& -1.2 & $(2.3)$ \\
\hline Value of Fruit Exports & $(2.4)$ & $938.8^{* * *}$ \\
& $548.5^{* * *}$ & $(51.3)$ \\
\hline Value of Wheat Exports & $(58.7)$ & -20.3 \\
& -12.1 & $(17.6)$ \\
\hline Mining Intensity & $(16.4)$ & $-254861^{* *}$ \\
& & $(69111)$ \\
\hline Constant & & -11473 \\
& $-202790^{* * *}$ & $(43540)$ \\
\hline R2- within, between, overall & $(6711)$ & 0.89 \\
\hline Rho & $0.43,0.74,0.67$ & $50(20)$ \\
\hline Groups (obs per group) & $50(20)$ & $0.90,0.86$ \\
\hline
\end{tabular}


Other explanatory variables operate as expected. Increases in population increase environmental spending, while unemployment decreases it. An increase in the number of bureaucrats increases state spending. The value of fruit exports significantly increases natural resource spending, while the value of wheat exports insignificantly decreases it. In the random effects model, mining intensity decreases natural resource spending.

As expected, both models predict the same high autocorrelation levels and correct for first order autocorrelation with a rho of 0.89 .

\section{Conclusions}

Our results suggest non-linear income effects for environmental quality. An EKC can best be described as a moving frontier of what people have (endowment), what people want (demand), and what is feasible (technology/supply). If we reformulate our thinking in this way, the puzzle of where and when we see EKCs should be considerably demystified.

From the random effects model, we can support the hypothesis that at higher incomes, environmental quality is a luxury good, and that as incomes rise, so too will demand for environmental quality. Additionally, the peaks for the EKCs determined in previous estimates occur at much lower levels of state per capita income than the troughs for state environmental spending that we estimate, so we have not simply identified the inverse of the pollution-income relationship. Resource endowments matter.

The fixed effects model improves upon the random effects model by allowing resource endowments to differ across states. While we would ideally estimate demand and supply equations for environmental quality simultaneously, the lack of a set price for environmental quality, as well as the multidimensional nature of the meaning of environmental quality, renders reduced-form estimation the only option. Still, we are able to identify supply side and demand side variables that show both must be considered in assessing the existence of the EKC. We find generic support for the EKC from the non-linearity of the income effects in the fixed effects model.

\section{References}

[1] Aldy, J.E., An Environmental Kuznets Curve Analysis of U.S. State-Level Carbon Dioxide Emissions. Journal of Environment and Development, 14(1): 48-72, 2005.

[2] Clingermayer, J.C., and B.D. Wood, Disentangling Patterns of State Debt Financing. American Political Science Review, 89(1): 108-20, 1995

[3] Cole, M.A., A.J. Rayner and J.M. Bates, The Environmental Kuznets Curve: An Empirical Analysis. Environment and Development Economics, 2(4): 401-16, 1997.

[4] Harbaugh, W.T., A. Levinson, and D.M. Wilson, Reexaming the Empirical Evidence for an Environmental Kuznets Curve. Review of Economics and Statistics, 84(3): 541-551, 2002. 
[5] Kuznets, S., Economic Growth and Income Inequality. American Economic Review 45(1): 1-28, 1955.

[6] List, J.A., and C.A. Gallet, The Environmental Kuznets Curve: Does One Size Fit All? Ecological Economics, 31(3): 409-23, 1999.

[7] Roca, J., Do Individual Preferences Explain the Environmental Kuznets Curve? Ecological Economics, 45(1): 3-10, 2003.

[8] Shafik, N., Economic Development and Environmental Quality: An Econometric Analysis. Oxford Economic Papers, 46(4): 201-227, 1994.

[9] Wright, G., The Origins of American Industrial Success, 1879-1940. American Economic Review, 80(4): 651-68.

[10] Yandle, B., Bhattarai, M. and M. Vijayaraghavan, Environmental Kuznets Curves: A Review of Findings, Methods, and Policy Implications, PERC UPDATE, Research Study 02-1, 2004. 